\title{
A double-tracer technique to determine the relative importance of water and food as sources of polonium-210 to marine prawns and fish
}

\author{
Fernando P. Carvalho*, Scott W. Fowler \\ International Atomic Energy Agency, Marine Environment Laboratory, PO Box 800, MC-98012 Monaco Cedex
}

\begin{abstract}
Accumulation of polonium in the common prawn Palaemon serratus and the sea perch Serranus scriba was studied experimentally to clarify the relative importance of water and food as sources of the high ${ }^{210}$ Po concentrations usually found in marine organisms. A double-tracer technique was used which enables differentiating the bioaccumulation of Po dissolved in seawater (as ${ }^{210} \mathrm{Po}$ ) and the digestive transfer of Po from food (as ${ }^{208} \mathrm{Po}$ ). Accumulation of dissolved Po by prawns was found to occur mainly through adsorption on the exoskeleton with a minor accumulation in internal tissues through the intake of seawater for osmoregulation. In contrast, ${ }^{208} \mathrm{Po}$ in labelled food was readily absorbed and accumulated in the internal tissues of prawns. Similar experiments with fish indicated that ${ }^{210}$ Po dissolved in seawater did not contribute directly to Po accumulated in internal organs. Instead, nearly all internally bound Po resulted from the assimilation of ${ }^{208} \mathrm{Po}$-labelled food. Measured Po absorption efficiencies were approximately 0.35 and 0.05 of the ingested dose for prawns and fish, respectively, and roughly corresponded to the assimilation efficiencies of proteins from food. In both prawns and fish, ingested ${ }^{208} \mathrm{Po}$ distributed in the tissues in a manner similar to naturally occurring ${ }^{210} \mathrm{Po}$ in control organisms, whereas ${ }^{210}$ Po dissolved in seawater partitioned differently. Modelling uptake through both pathways demonstrated that $P_{0}$ in the food accounted for $>97 \%$ of the Po measured in these 2 organisms. These experimental results suggested that, in nature, accumulation of Po by marine organisms in higher trophic levels depends upon the previous Po binding to organic matter in lower trophic levels; therefore, Po transfer through marine food-chains is primarily a function of the food assimilation efficiency and feeding rate of the organisms. The double-tracer technique described here is a useful experimental tool in the study of Po transfer pathways in marine organisms, and could also be applied to the study of other aspects of Po biogeochemistry
\end{abstract}

KEY WORDS: Natural radioactivity · Polonium · Food-chain energetics · Radiotracers · Biogeochemical cycles

\section{INTRODUCTION}

The naturally occurring polonium-210 $\left({ }^{210} \mathrm{Po}\right)$ in seawater originates from the radioactive decay of dissolved ${ }^{226} \mathrm{Ra}$ and from the atmospheric deposition of ${ }^{210} \mathrm{~Pb}$ and ${ }^{210} \mathrm{Po}$. Several studies have illustrated the accumulation of ${ }^{210} \mathrm{P}_{\mathrm{O}}$ in a wide variety of marine organisms (Hoffman et al. 1974, Heyraud \& Cherry

- On leave from Instituto Nacional de Engenharia e Tecnologia Industrial, Departamento de Proteccao e Seguranca Radiologica, EN 10, P-2685 Sacavem, Portugal
1979, Cherry \& Heyraud 1981, Carvalho 1988a, b, 1990, Skwarzec \& Bojanowski 1988) and have highlighted the exceptionally elevated concentrations in some organs, e.g. the hepatopancreas of crustaceans (Cherry \& Heyraud 1981. Heyraud et al. 1988) and in the liver and gonad of fish (Carvalho 1988a, 1990). These elevated ${ }^{210}$ Po concentrations create the highest known natural radiation doses in the biosphere (Cherry \& Heyraud 1982, Carvalho 1988a); nevertheless, the mechanisms involved in the buildup of ${ }^{210} \mathrm{Po}$ concentrations in marine organisms remain essentially unstudied. Recently, the kinetics of ${ }^{210} \mathrm{Po}$ and ${ }^{210} \mathrm{~Pb}$ 
accumulation from water and from food and water were experimentally studied in benthic shrimp (Carvalho \& Fowler 1993). It was found that ${ }^{210}$ Po accumulation in shrimp tissues was substantially increased by the ingestion of labelled food, whereas the concentration of ${ }^{210} \mathrm{~Pb}$ was not significantly altered.

The interest in the accumulation of ${ }^{210} \mathrm{Po}$ in aquatic organisms has broadened in response to the observation of enhanced ${ }^{21.0} \mathrm{Po}$ concentrations associated with waste discharges from non-nuclear industries into water bodies (Koster et al. 1992). Moreover, in view of the potential use of ${ }^{210} \mathrm{Po}$ as a natural tracer of the diet of marine organisms (Heyraud et al. 1988, Cherry et al. 1989), as well as in marine biogeochemical cycling studies (Broecker \& Peng 1982, Fowler \& Knauer 1986. Todd et al. 1986), a better understanding of ${ }^{210} \mathrm{Po}$ accumulation and transfer in marine biota is necessary.

To investigate the pathways and rates involved in ${ }^{210} \mathrm{Po}$ accumulation and to identify the relative importance of water and food as sources of this radionuclide to marine organisms, we conducted a series of controlled radiotracer experiments in the laboratory using prawns and fish. For the study of Po bioaccumulation, we have developed a double-tracer technique which allows following, simultaneously, the direct uptake of dissolved ${ }^{210} \mathrm{Po}$ in seawater and the accumulation of ${ }^{208}$ Po through ingestion of radiolabelled food. Such a technique relies on identical chemical properties and physiological behaviour displayed by different isotopes of the same element. The use of this doubletracer procedure, beyond the cost of radioisotopes, requires an alpha-spectrometer and skills in radiochemistry which are generally available in laboratories equipped for radioactivity measurements.

\section{MATERIAL AND METHODS}

Radiotracers and radioanalytical techniques. A standard solution of ${ }^{210} \mathrm{~Pb}\left(T_{1 / 2}=22.2 \pm 0.2\right.$ a) as lead nitrate in $3 \mathrm{M} \mathrm{HNO}_{3}$ was purchased from ORIS, France. The specific activity of the ${ }^{210} \mathrm{~Pb}$ was $0.737 \mathrm{MBq} \mathrm{g}^{-1}$ of solution and the radionuclide was in radioactive equilibrium with its progeny ${ }^{210} \mathrm{Bi}\left(T_{1 / 2}\right.$ $=5.01 \mathrm{~d})$ and ${ }^{210} \mathrm{Po}\left(T_{1 / 2}=138.4 \mathrm{~d}\right)$.

A solution of pure ${ }^{210} \mathrm{Po}$ was separated from an aliquot of the ${ }^{210} \mathrm{~Pb}$-Bi-Po stock solution using an ionexchange (Dowex AG $1 \times 8,100-200$ mesh) column chromatographic procedure (Carvalho 1990). The aliquot of stock solution was converted into chloride, passed through the ion-exchange column, and ${ }^{210} \mathrm{~Pb}$, ${ }^{210} \mathrm{Bi}$ and ${ }^{210} \mathrm{Po}$ sequentially eluted. The ${ }^{210} \mathrm{Po}$, eluted with $\mathrm{HNO}_{3}$, was reconverted into the chloride form. A working solution of 'unsupported' ${ }^{210} \mathrm{Po}$ (i.e. free of the parent radionuclides ${ }^{210} \mathrm{~Pb}$ and ${ }^{210} \mathrm{Bi}$ ) was then pre-

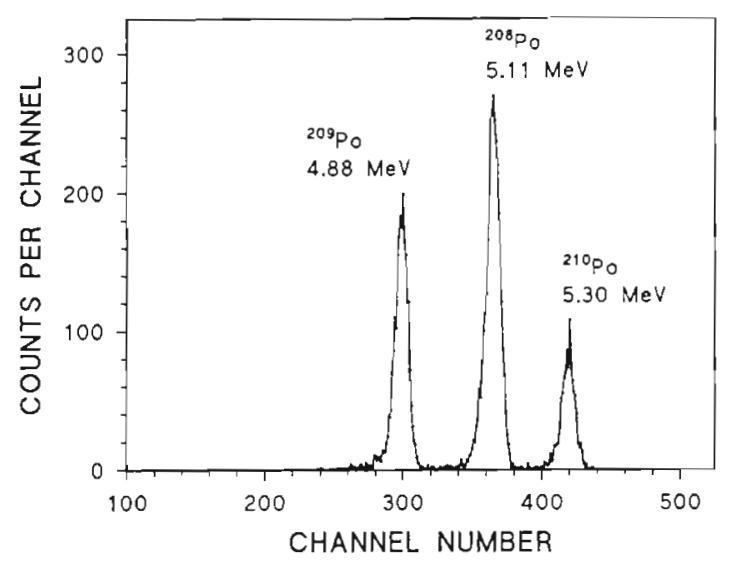

Fig. 1. Alpha spectra of polonium isotopes plated on a silver disc and obtained through a $300 \mathrm{~mm}^{2}$ active surface silicon barrier detector. Sample of stomach and pyloric caeca from Serranus scriba analysed in the course of this work

pared in $0.5 \mathrm{M} \mathrm{HCl}$ for use in the experiments. The purity of this solution was checked and the concentration of ${ }^{210}$ Po determined by alpha spectrometry.

Two other polonium isotopes, ${ }^{208} \mathrm{Po}$ and ${ }^{209} \mathrm{Po}$, both artificially produced and non-existent in the natural environment, were used in the experiments. ${ }^{208} \mathrm{Po}$ $\left(T_{1 / 2}=2.89\right.$ a) was purchased from Harwell (UK) $99.8 \%$ pure in $1 \mathrm{M} \mathrm{HCl}$ solution, and ${ }^{209} \mathrm{Po}\left(T_{1 / 2}=102 \mathrm{a}\right)$ was obtained from Oak Ridge (USA) in $1 \mathrm{M} \mathrm{HNO}_{3}$ solution. Both tracers were checked for the presence of contaminating alpha emitters, and it was found that these contaminants accounted for much less than $0.1 \%$ of the total alpha activity. Dilute working solutions of these radioisotopes were prepared in $0.5 \mathrm{M} \mathrm{HCl}$ for the experiments.

The use of the 2 polonium isotopes, ${ }^{208} \mathrm{Po}$ and ${ }^{210} \mathrm{Po}$, allowed simultaneously tracing uptake from 2 different sources of polonium; the third isotope, ${ }^{209} \mathrm{Po}$, was used as a yield determinant for radiochemical recovery. The energies of the alpha-particle emmissions of these 3 isotopes are sufficiently separable to allow good spectra resolution and the determination of the activity of each isotope in the samples (Fig. 1). The addition of 1 artificially produced Po isotope, usually ${ }^{208} \mathrm{Po}$, as an internal standard for the radiochemical yield determination is commonly made during the alpha analysis of natural ${ }^{210}$ Po (Fleer \& Bacon 1984). However, because of the wider separation of energies, ${ }^{209} \mathrm{Po}$ is the most suitable for this purpose. Since both ${ }^{208} \mathrm{Po}$ and ${ }^{209} \mathrm{Po}$ are now commercially available, their simultaneous use with ${ }^{210}$ Po was possible in our experiments.

For determination of $\mathrm{Po}$ isotope activities in the samples, following a standard addition of ${ }^{209} \mathrm{Po}$, the samples were completely dissolved with mineral acids and Po spontaneously plated onto a silver disc in $0.5 \mathrm{M} \mathrm{HCl}$ 
and ascorbic acid (Flynn 1968, Carvalho 1988). Alpharadioactivity measurements were made on silicon surface-barrier detectors connected to a multichannel analyser. The detectors were calibrated with an electroplated ${ }^{239} \mathrm{Pu}$ reference source. Counting times of samples were adjusted to obtain relative standard errors of approximately $5 \%$, and concentrations of $\mathrm{Po}$ isotopes are reported per unit fresh weight of tissue.

Organisms and experimental procedures. Accumulation of Po from water and food by prawns: The carnivorous common prawn Palaemon serratus (Pennant, 1777) (Palaemonidae) was chosen for the study because it is capable of ingesting relatively large pieces of food. All experiments were performed in a temperature-controlled $\left(14^{\circ} \mathrm{C}\right)$ laboratory under a simulated 12 h day : 12 h night cycle.

In a preliminary experiment 3 prawns were placed separately in individual $5 \mathrm{l}$ aquaria to follow the absorption of ingested polonium into the internal organs. Soft tissues of mussels, previously exposed for 1 wk to unsupported ${ }^{210} \mathrm{Po}$-spiked seawater and fed with labelled phytoplankton (mixed culture of diatoms and dinoflagellates grown in ${ }^{210}$ Po contaminated seawater), were used as food for the prawns. The average activity of ${ }^{210} \mathrm{Po}$ in weighed rations of mussel flesh (320 to $388 \mathrm{mg}$ wet $w \mathrm{t}$ ) supplied to prawns was estimated based on previous measurement of ${ }^{210} \mathrm{Po}$ specific activity in mussels, i.e. $212 \mathrm{~Bq} \mathrm{~g}^{-1}$. After the single radioactive feeding, prawns were held in flowing seawater $\left(30 \mathrm{l} \mathrm{h}^{-1}\right)$ and fed daily ad libitum with nonlabelled food. A measurement of ${ }^{210}$ Po eliminated with the feces of the prawns was made daily for $5 \mathrm{~d}$. In order to complete the budget, on Day 6 prawns were sacrificed and ${ }^{210}$ Po analysed in the individual tissues.

In a second experiment a larger group of prawns (mean individual wet wt $3.83 \pm 2.35 \mathrm{~g}, \mathrm{n}=14$ ) was used to investigate the relative importance of food and water as pathways for the uptake of polonium. Using the solution of unsupported ${ }^{210} \mathrm{Po}$, the concentration in the seawater medium was increased to $12 \pm 1.3 \mathrm{~Bq}^{-1}$, i.e. $1.2 \times 10^{4}$ times the typical concentration of the naturally occurring ${ }^{210} \mathrm{Po}$. Prawns were exposed for $22 \mathrm{~d}$ in the spiked seawater medium which was renewed fresh every 2 to $3 \mathrm{~d}$. Analyses of water samples filtered through $0.45 \mu \mathrm{m}$ pore size membrane filters indicated that, throughout the experiment, more than $85 \%$ of ${ }^{210}$ Po was present in the dissolved phase. In addition, during the experiment the prawns in the spiked seawater were regularly fed mussel soft tissue previously labelled with ${ }^{208} \mathrm{Po}$ (via water and ingested phytoplankton). Eleven identical meals were supplied in this way throughout $21 \mathrm{~d}$. Aquaria were inspected twice daily and feces removed to avoid radionuclide recycling by prawns. The concentration of ${ }^{208}$ Po in the mussel flesh was $2.5 \pm 1.6 \mathrm{~Bq} \mathrm{~g}^{-1}$ and the corresponding concentration of the naturally occurring ${ }^{210}$ Po was 0.13 $\pm 0.06 \mathrm{~Bq} \mathrm{~g}^{-1}(\mathrm{n}=5$ analyses) Periodically, 2 prawns were sacrificed and their tissues dissected and bulked in order to average inter-individual variability in the analyses of Po isotopes. The analyses of prawn tissues at time zero provided information on the concentration of the naturally occurring ${ }^{210} \mathrm{Po}$.

Accumulation of Po from water and food by fish: The relative contributions of Po from ingested food and from the radionuclide dissolved in seawater were measured in the sea perch Serranus scriba (Linnaeus, 1758) (Osteichthyes) following an experimental protocol similar to that described above for the prawn.

An initial group of fish (Group I, mean individual wet wt $23 \pm 3 g, n=12$ ) was used to measure the absorption of Po through the digestive pathway, as well as to verify whether Po absorbed via food could adequately trace the distribution and turnover of natural ${ }^{210} \mathrm{Po}_{\mathrm{o}}$ in the internal organs of fish. Prior to the start of the experiment, fish were fed for $2 \mathrm{wk}$ with a fresh supply of natural prey, viz, euphausiids (Meganyctiphanes norvegica) and small shrimp (Lysmata seticaudata) These organisms contained, on the average, concentrations of natural ${ }^{210} \mathrm{Po}$ at $\mathrm{ca} 0.07 \mathrm{~Bq} \mathrm{~g} \mathrm{~g}^{-1}$ wet wt Therefore, the ingestion of such fresh food was expected to help maintain the ${ }^{210} \mathrm{Po}$ content in fish tissues at normal levels.

Artificially labelled food was prepared from shrimp Lysmata seticaudata labelled for $1 \mathrm{wk}$ in seawater containing dissolved ${ }^{200} \mathrm{Po}$ and fed Artemia sp. previously labelled with ${ }^{208} \mathrm{Po}$ from water and phytoplankton. Shrimp tissues, in particular the visceral organs, were homogenized and food pellets were prepared from the homogenate using gelatin as an agglutinant. Each fish was subsequently fed 1 of these pellets, $(0.8 \mathrm{ml}$ volume containing approximately $158 \mathrm{~Bq}{ }^{208} \mathrm{Po}$ ) and then maintained under running seawater. Two days after ingestion of the pellets, fish were continually fed for $27 \mathrm{~d}$ with non-labelled, pelletized $L$. seticaudata muscle from a frozen stock. This food had a low content of natural ${ }^{210} \mathrm{Po}$, approximately $0.008 \mathrm{~Bq} \mathrm{~g}^{-1}$, and therefore allowed the initial ${ }^{210} \mathrm{Po}$ level in fish to decrease throughout the experiment. Analyses of $\mathrm{Po}$ in fish tissues were made at time zero for determination of natural level of ${ }^{210} \mathrm{Po}$, and periodically throughout the experiment for both ${ }^{208} \mathrm{Po}$ and ${ }^{210}$ Po taken up.

A second group of fish (Group II, mean individual wet wt $22 \pm 7 \mathrm{~g}, \mathrm{n}=16$ ) was exposed to elevated concentrations of ${ }^{210} \mathrm{Po}$ dissolved in seawater and regularly fed shrimp labelled with ${ }^{208}$ Po. Before the start of the experiment, fish were acclimated in individual $5 \mathrm{l}$ aerated aquaria. During the experiment water was renewed 3 times $w k^{-1}$, and the concentration of spiked ${ }^{210} \mathrm{Po}$ in seawater was maintained nearly constant at $8.3 \pm 2.1 \mathrm{~Bq}^{-1}$ for $26 \mathrm{~d}$. Fish were periodically fed 
Lysmata seticaudata previously labelled with ${ }^{208} \mathrm{Po}$ as described above. Each fish rapidly ingested 1 shrimp approximately every $2 \mathrm{~d}$ (feeding rate 0.023 to $0.050 \mathrm{~g}$ $\mathrm{g}^{-1}$ fish $\mathrm{d}^{-1}$ ). The average concentration of ${ }^{208} \mathrm{Po}$ in these shrimp was $1.7 \pm 0.5 \mathrm{~Bq} \mathrm{~g}^{-1}$ wet wt and their natural ${ }^{210} \mathrm{Po}$ content was $0.066 \pm 0.026 \mathrm{~Bq} \mathrm{~g}^{-1}$ wet wt ( $\mathrm{n}=$ 6 analyses). Repeated analyses of water indicated that radiotracer cycling between food, water and fish was negligible. At each sampling time, fish were sacrificed with a lethal dose of anesthetic and dissected tissues from 2 specimens were pooled for a single analysis of the Po isotopes. The non-separated tissues (head, gills, skin, scales, fins), termed remainder, were also analysed to enable a reconstitution of the total body burden of Po in the fish.

Modelling polonium accumulation in organisms. In general, the kinetics of radionuclide and trace element turnover in marine organisms can be fit to exponential models (Pentreath 1973, Carvalho \& Fowler 1985, Swift \& Pentreath 1988). In modelling the bioaccumulation of radionuclides, it is necessary to take into consideration the rates for uptake (both from water and food) and the elimination processes (excretion, radioactive decay). Growth and reproduction also contribute to the change of radionuclide concentration over time in organisms; however, the latter do not apply to short-term experimental exposure periods during which no significant changes in body size and reproduction are observed. Therefore, disregarding growth and reproduction, the kinetics of Po uptake and elimination in an organism can be generalized using the mass balance equation

$$
\mathrm{d} Q_{t} / \mathrm{d} t=I_{\mathrm{w}} W C_{w}+A F C_{\mathrm{t}}-(k+\lambda) Q_{t}
$$

where $Q_{t}=$ activity of Po in the organism $(\mathrm{Bq})$ at time $t_{\text {; }}$ $I_{\mathrm{w}}=$ the uptake rate constant from water $\left(\mathrm{ml} \mathrm{g}^{-1}\right.$ organism $\mathrm{d}^{-1}$ ) by all processes, viz. drinking and surface adsorption; $W=$ weight of organism $(g) ; C_{w}=$ Po concentration in water $\left(\mathrm{Bq} \mathrm{ml} \mathrm{ml}^{-1}\right) ; A=$ digestive assimilation efficiency (or absorption efficiency) of Po from food $F=$ the amount of food ingested by an organism per day $\left(g \mathrm{~d}{ }^{1}\right)_{i} C_{t}=$ concentration of Po in tood $(\mathrm{mBq}$ $\left.\mathrm{g}^{-1}\right) ; k=$ elimination rate constant of Po $\left(\mathrm{d}^{-1}\right)$ from the organism; $\lambda=$ the radioactive desintegration rate constant of. Po $\left(\lambda_{210 \mathrm{po}}=0.00501 \mathrm{~d}^{-1} ; \lambda_{2088} \mathrm{po}=0.000656 \mathrm{~d}^{-1}\right)$.

In practice, the difficulty in modelling the bioaccumulation of Po (or of any other element) in a specific organism, and the subsequent Po transfer in marine food chains, resides in the unknown contributions from food and from water to the amount of $Q_{\imath}$ measured in the organism. This difficulty can be circumvented when each source is traced by a different isotope. The kinetics of each isotope and the contribution from each uptake pathway can then be resolved.
We can evaluate separately each term in Eq. (1). If we consider the uptake from water only (making $C_{i}=0$ ), the kinetics of Po in the organism is given by

$$
\mathrm{d} Q_{t} / \mathrm{d} t=I_{\mathrm{w}} W C_{w}-(k+\lambda) Q_{t} .
$$

Holding the concentration of Po in water constant, a steady state in exchange between water and organism will be attained where input of $\mathrm{Po}$ into the organism will be balanced by the output. Thus $\mathrm{d} Q_{t} / \mathrm{d} t=0$, and $Q_{t}$ is the steady-state Po body burden, $Q_{\mathrm{ss}}$. Therefore,

and finally

$$
\mathrm{Q}_{\mathrm{s} s}=\frac{I_{\mathrm{w}} C_{W} W}{k+\lambda}
$$

$$
Q_{t}=Q_{s s}\left(1-e^{-(k+\lambda) t}\right)
$$

Instead of Po body burden, this equation can be transformed to Po concentration $\left(C_{t}\right)$ by dividing by the weight of the organism $(W)$. Hence,

$$
C_{t}=\frac{I_{w} C_{w}}{k+\lambda}\left(1-\mathrm{e}^{-(k+\lambda) /}\right) .
$$

The concentration of $\mathrm{Po}_{\mathrm{in}}$ the organism can then be related to the concentration of Po in the water through a concentration factor $\left[C F=\left(B q g^{-1}\right.\right.$ organism $) /(B q$ $\mathrm{ml}^{-1}$ )] by dividing Eq. (4) by $C_{w}$. If we take into account any Po content in the organism at the beginning of the exposure period, then

$$
C F_{l}=\frac{I_{\mathrm{w}}}{k+\lambda}\left(1-\mathrm{e}^{-(k+\lambda) t}\right)+C F_{t_{0}} \mathrm{e}^{-(k+\lambda) t}
$$

where $C F_{t_{0}}=C F$ of Po in the organism at the start of the accumulation period $t$

When the accumulation period is interrupted and the organism transferred to unlabelled seawater, the concentration of Po decreases with time by excretion and radioactive decay. Therefore, with $C_{0}$ being the concentration at the start of the elimination period $t_{\text {, }}$

$$
C_{t}=C_{0} \mathrm{e}^{-(k+\lambda) t}
$$

The plot of $\ln C_{t}$ against time enables the calculation of $(k+\lambda)$ from the slope of the loss curve. Since the radioactive decay constant of Po isotopes $(\lambda)$ is well known, the biological half-life $\left(T_{b 1 / 2}\right)$ of $\mathrm{Po}$ in the organism can be calculated by $T_{\mathrm{b} 1 / 2}=(\ln 2) / \mathrm{k}$. Often it is observed that the retention of radionuclide is better described by the sum of several exponential functions, each one corresponding to the turnover of the isotope in a different compartment.

We can also consider that uptake from water is negligible ( $I_{\mathrm{w}}=0$ or $C_{w}=0$ ) and, from Eq. (1), the kinetics of Po bioaccumulation from food will follow

$$
\mathrm{d} Q_{t} / \mathrm{d} t=A F C_{\mathrm{f}}-(k+\lambda) Q_{i}
$$


Table 1 Palaemon serratus. Concentrations of ${ }^{210} \mathrm{Po}\left(\mathrm{Bq} \mathrm{g}^{-1}\right.$ wet wt) and tissue $\%$ of the whole body wet wt in 3 specimens analysed $6 \mathrm{~d}$ after a single feeding with ${ }^{210} \mathrm{Po}$-labelled mussel flesh. Balance of ingestion and retention. TBB: total body burden

\begin{tabular}{|c|c|c|c|c|c|c|c|}
\hline \multirow[t]{2}{*}{ Tissues } & \multicolumn{2}{|c|}{ Palaemon 1} & \multicolumn{2}{|c|}{ Palaemon 2} & \multicolumn{2}{|c|}{ Palaemon 3} & \multirow{2}{*}{$\begin{array}{c}{ }^{211} \mathrm{Po} \\
\text { average } \\
\% \mathrm{TBB}\end{array}$} \\
\hline & $\%$ weight & ${ }^{2111} \mathrm{Po}$ & $\%$ weight & ${ }^{2110} \mathrm{Po}$ & $\%$ weight & ${ }^{2110} \mathrm{Po}$ & \\
\hline Hepatopancreas & 1.5 & 118 & 2 & 125 & 2.6 & 50 & $53 \pm 13$ \\
\hline Gut & 1.7 & 75 & 6.7 & 6 & 1.3 & 33 & $18 \pm 6$ \\
\hline Muscle & 44 & 0.15 & 36.1 & 0.04 & 38.2 & 0.08 & $1 \pm 0.4$ \\
\hline Exoskeleton & 15.7 & 1.5 & 7.1 & 0.58 & 15.7 & 0.45 & $3 \pm 1.5$ \\
\hline Remainder & 37 & 4 & 48 & 1.4 & 42.1 & 1.3 & $24 \pm 5$ \\
\hline Whole body & $2.535 \mathrm{~g}$ & $11.38 \mathrm{~Bq}$ & $6.366 \mathrm{~g}$ & $22.55 \mathrm{~Bq}$ & $7.027 \mathrm{~g}$ & $15.08 \mathrm{~Bq}$ & \\
\hline \multicolumn{2}{|c|}{${ }^{210} \mathrm{Po}$ in the meal $(\mathrm{Bq})$} & 82 & & 80 & & 68 & \\
\hline \multicolumn{2}{|c|}{ 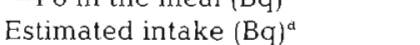 } & 75 & & 71 & & 64 & \\
\hline \multicolumn{2}{|c|}{ Measured in feces $(\mathrm{Bq})^{\mathrm{b}}$} & 15.2 & & 18.4 & & 18.6 & \\
\hline \multirow{2}{*}{\multicolumn{2}{|c|}{$\begin{array}{l}\% \text { of intake retained in } \\
\text { tissues at Day } 6\end{array}$}} & & & & & & \\
\hline & & 15 & & 32 & & 23 & \\
\hline
\end{tabular}

It should be kept in mind that the ingestion rate of food, $F$, is not constant throughout the lifetime of an organism and, indeed, it is not even constant throughout the year. Likewise, the composition of ingested food (and thus $C_{f}$ ) is not constant. Nevertheless, it is reasonable to assume that these parameters do not vary considerably over short time periods.

Food is used for maintenance (energetic cost of metabolism) and growth, but not all of the ingested food is absorbed. Therefore, we can represent the input of Po into an organism through the consumption of food $\left(I_{\mathrm{f}}\right)$, by $I_{\mathrm{f}}=A F C_{\mathrm{f}}$ as used above (Eq. 7). At steady state $\mathrm{d} Q_{t} / \mathrm{d} t=0$, and $Q_{t}$ corresponds to the steady-state Po body burden $Q_{s s}$, and $Q_{s s}=A F C_{1}$ $(k+\lambda)^{-1}$. Dividing by the organism weight $(W)$, this equation can be converted into concentration (C)

$$
C_{s s}=\frac{A C_{1}}{k+\lambda} \times \frac{F}{W}
$$

where $F / W=$ feeding rate, $F_{\mathrm{r}}\left(\mathrm{g}\right.$ food $\mathrm{g}^{-1}$ organism $\left.\mathrm{d}^{-1}\right)$. Therefore, for short time intervals we can calculate the Po concentration in the organism $\left(C_{t}\right)$ obtained from food by

$$
C_{t}=\frac{A C_{\mathrm{f}}}{k+\lambda} F_{\mathrm{r}}\left(1-\mathrm{e}^{-(k+\lambda) t}\right)
$$

Thus, under the assumptions mentioned above, determination of the rate constants for each Po accumulation pathway will allow evaluating the contributions from food and water to the Po content in the organism.

\section{RESULTS}

\section{Accumulation of Po from water and from food by prawns}

Results from the preliminary experiment to examine the digestive absorption of Po by Palaemon serratus are given in Table 1 . The highest concentrations of ${ }^{210} \mathrm{Po}$ were measured in hepatopancreas and gut, which together contributed to most $(71 \%)$ of the whole-body ${ }^{210}$ Po activity, whereas muscle tissue displayed the lowest Po concentration comprising only $1 \%$ of the whole body burden. All the concentrations are, of course, much higher than concentrations of natural ${ }^{210} \mathrm{Po}$ in the prawn (see concentrations for Day $0_{i}$ Table 2). Considering that prawns had been fed only 1 meal of ${ }^{210}$ Po-labelled food and that they have a gut transit time of the meal $<24 \mathrm{~h}$, the high efficiency of digestive absorption of Po into internal tissues is apparent. Six days after ingesting the labelled meal, ${ }^{210}$ Po retained in shrimp tissues was still 15 to $32 \%$ of the ingested dose (Table 1). During the 6 d elapsed between ingestion and dissection, ${ }^{210}$ Po in feces egested by prawns decreased over time with a first order rate constant of $-0.30 \mathrm{~d}^{-1}$. In total, 20 to $29 \%$ of the ingested dose was measured in feces, whereas 42 to $64 \%$ was excreted with the urine and/or was redissolved from solid excreta (Table 1). Using Eq. (6), the ${ }^{210} \mathrm{Po}$ concentration retained in $P$. serratus at Day 6 , and applying a biological half-life for ${ }^{210} \mathrm{Po}$ of $10 \mathrm{~d}$ determined previously in another decapod crustacean (Carvalho \& Fowler 1993), we computed the amount of ${ }^{210} \mathrm{Po} a b-$ sorbed at time zero $\left(C_{0}\right)$ and estimated the absorption efficiency $(A)$ to be 0.35 of the ingested dose. 


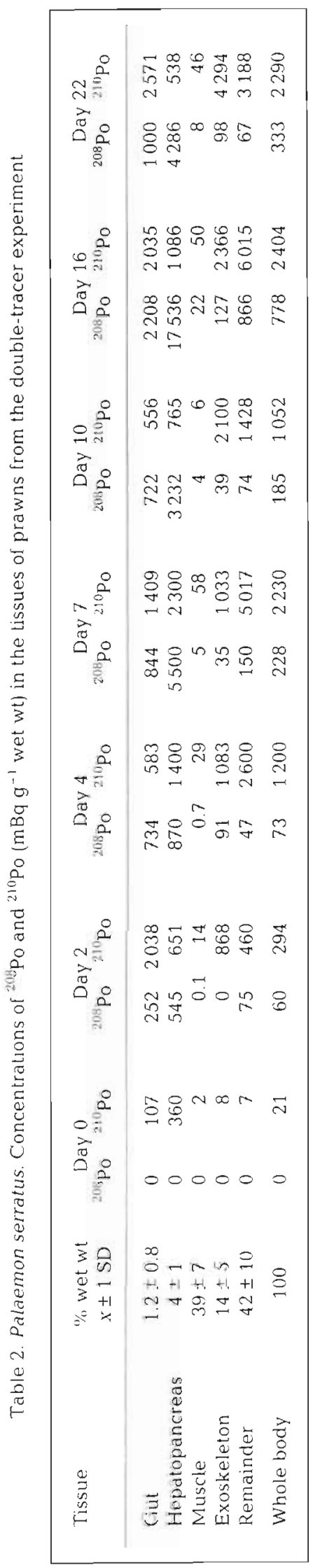

Results from the second experiment with prawns enabled us to make a comparative evaluation of both water and food as potential contributors to the accumulation of Po by prawns (Table 2). The change of polonium concentrations in tissues over time showed that ${ }^{210}$ Po dissolved in water was mainly adsorbed on external surfaces and did not contribute significantly to Po accumulation in internal organs. On the other hand, ${ }^{208} \mathrm{Po}$ in the food was efficiently absorbed, as demonstrated by increased concentrations in internal tissues over time, whereas it contributed little to the Po content in the external surfaces (exoskeleton, remainder).

The relative contribution of each Po isotope to the whole-body burden over time is shown in Fig. 2. Comparing the distribution of each isotope with the distribution of the naturally occurring ${ }^{210}$ Po at time zero (control), it is evident that the distribution of ${ }^{208}$ Po absorbed from food consistently reproduced the distribution of naturally occurring ${ }^{210} \mathrm{Po}$. Furthermore, the data indicate that polonium dissolved in the water was not the main source for the Po concentrated in internal tissues of prawns. Clearly, it is the digestive absorption of Po (seen here as ${ }^{208} \mathrm{Po}$ ) incorporated in the organic matrix of the food that results in the incorporation of Po in prawn organs in the natural environment.

Whole-body CF of ${ }^{210}$ Po accumulated from seawater by prawns are shown in Fig. 3. Accumulation took place both in internal tissues and on external surfaces (Table 2). ${ }^{210}$ Po accumulated in internal tissues is most likely related to the intake of seawater for osmotic regulation as has been shown for benthic shrimp (Carvalho \& Fowler 1993). From measurements of the $\mathrm{NaCl}$ extra-renal efflux in Palaemon serratus, $20 \mu \mathrm{M} \mathrm{NaCl}$ $\mathrm{h}^{-1} \mathrm{~g}^{-1}$ (Spaargaren 1972), we estimated the drinking rate of water to be $0.74 \mathrm{ml} \mathrm{g}^{-1} \mathrm{~d}^{-1}$ at ca $13^{\circ} \mathrm{C}$ and $38 \%$ salinity. This water intake rate would enable dissolved ${ }^{210}$ Po to accumulate in the internal tissues of prawns at the rate of $8.8 \mathrm{mBq} \mathrm{g}^{-1}$ prawn $\mathrm{d}^{-1}$. Taking into account the biological half-life of ${ }^{210}$ Po $(10 \mathrm{~d})$, the decay constant of ${ }^{210} \mathrm{Po}$, and the initial content of naturally occurring ${ }^{210} \mathrm{Po}$ in prawns, we compute by Eq. (4) that the intake of seawater would result in a ${ }^{210} \mathrm{Po}$ concentration of $114 \mathrm{mBq} \mathrm{g}^{-1}$ in prawns after $22 \mathrm{~d}$ of exposure. Considering model Eq. (5), this intake route would lead to a whole-body CF of 9.5 at Day 22 (Fig. 3). This predicted ${ }^{210}$ Po concentration can not be directly compared with ${ }^{210}$ Po measurements in whole prawns due to the contribution of external adsorption. However, at Day $22{ }^{210}$ Po accumulated in the bulk of internal tissues (i.e. hepatopancreas and muscle, taking into account their relative weight and specific activities; Table 2) was $113 \mathrm{mBq} \mathrm{g}^{-1}$ and $C F$ was 9.4. These values derived from measurements are in excellent agreement with the model predictions. Moreover, the higher than expected whole-body ${ }^{210}$ Po concentration. 
measured in prawns ( $C F=242$ at Day 22; Fig 3) indicates an important accumulation of ${ }^{210} \mathrm{Po}$ by another process. This process, accounting for $96 \%$ of the ${ }^{210} \mathrm{Po}$ CF observed at Day 22, corresponds to the adsorption of ${ }^{210} \mathrm{Po}$ onto the external surfaces of prawns. In fact, the percent contribution of exoskeleton plus remainder (essentially external tissues) to the ${ }^{210}$ Po whole-body burden is 96 to $98 \%$ from Day 10 onwards (Fig. 2). Therefore, the input rate of ${ }^{210} \mathrm{Po}$ from water into prawns, $I_{w}$, is in this case the sum of 2 components, water intake and external adsorption which account for ca $3 \%$ and ca $97 \%$ of the $I_{w}$ respectively.

The accumulation of ${ }^{208} \mathrm{Po}$ in prawns and their tissues over time is presented in Fig. 4. Prawns were fed ad libitum with labelled food, but the exact amount of food ingested is not accurately known. Nevertheless, the experimental points can be fitted (Eq. 9) assuming a feeding rate of $5 \%$ of Palaemon serratus body wt $\mathrm{d}^{-1}$ and assimilation efficiency $A=0.35$ as determined in the first experiment with prawns (Fig. 4A.). Fig. 4B shows the change in ${ }^{208} \mathrm{Po}$ concentration in prawn tissues over time, and demonstrates the rapid absorption of ${ }^{208} \mathrm{Po}$ from food into the hepatopancreas and the slower accumulation of ${ }^{208} \mathrm{Po}$ in muscle tissue.

The rate constants determined in these experiments can be applied with the same models to the environmental concentrations of ${ }^{210}$ po to predict the contributions of water and food to the natural ${ }^{210} \mathrm{Po}$ content in prawns. Taking $1.0 \times 10^{-6} \mathrm{~Bq} \mathrm{ml}{ }^{-1}$ as the concentration of ${ }^{210} \mathrm{Po}$ in seawater and assuming a $C F_{s s}=265$, the resultant concentration in prawns would be approximately $0.3 \mathrm{mBq} \mathrm{g}^{-1}$. Through consumption of prey (e.g. mollusc soft tissues) containing ${ }^{210} \mathrm{Po}$ concentrations of 50 to $100 \mathrm{mBq} \mathrm{g}^{-1}$, the whole-body steady-state concentration in prawns would be ca 12 to $23 \mathrm{mBq} \mathrm{g}^{-1}$ supported by food. Therefore, the dissolved fraction of ${ }^{210} \mathrm{Po}$ in seawater would account for only about 1 to $2 \%$ whereas food will contribute 98 to $99 \%$ of the total body burden in prawns.

\section{Accumulation of Po from water and from food by fish}

Concentrations of ${ }^{208} \mathrm{Po}$ in tissues and in the whole body of Serranus scriba fed a single meal of ${ }^{208} \mathrm{Po}$ labelled food are given in Table 3 along with concentrations of natural ${ }^{210} \mathrm{Po}$. Three days after the ingestion of a single ration, ${ }^{208} \mathrm{Po}$ was detected in all internal tissues. The highest ${ }^{208}$ Po concentration was measured at Day 3 in liver, accounting for about $85 \%$ of the wholebody burden of ${ }^{208} \mathrm{Po}$ in fish. Following the concentration peak observed at Day $3,{ }^{208}$ Po in liver decreased rapidly $\left(T_{\mathrm{b} 1 / 2}=1 \mathrm{~d}\right)$ during the following days followed by a period of slower ${ }^{208}$ Po elimination $\left(T_{b 1 / 2}=10 \mathrm{~d}\right)$. This slow component of loss is comparable to the elim-
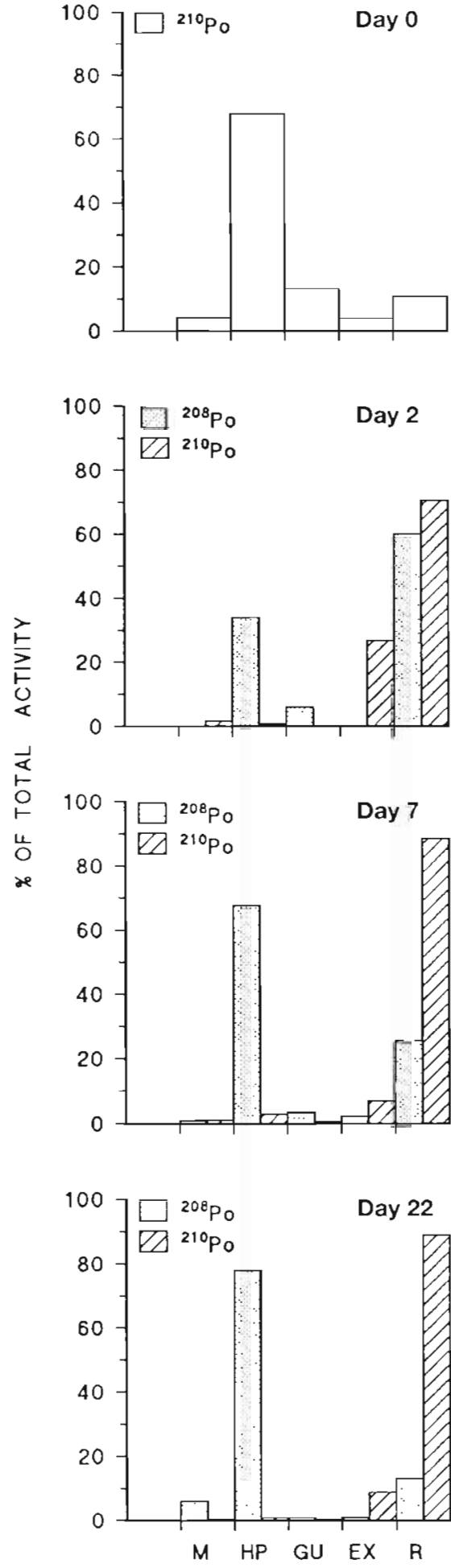

Fig. 2. Palaemon serratus. Percent contribution of each tissue to the whole-body activities of ${ }^{208} \mathrm{Po}$ and ${ }^{210} \mathrm{Po}$ in the doubletracer experiment. Distribution of ${ }^{210} \mathrm{Po}$ at time zero (control) represents the naturally occurring ${ }^{210} \mathrm{Po}_{\text {; }}$ thereafter, ${ }^{203} \mathrm{Po}$ ingested with food and ${ }^{210} \mathrm{Po}$ taken up from seawater. M: muscle; HP: hepatopancreas; GU: gut; EX: exoskeleton; $R$ : remainder 


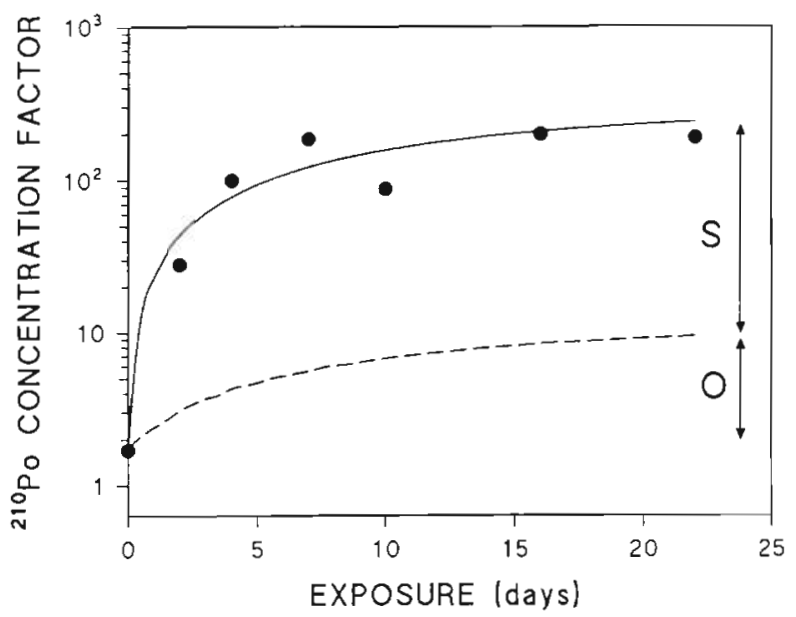

Fig. 3. Palaemon serratus. Concentration factor $(C F)$ for ${ }^{210} \mathrm{Po}$ accumulated from water by prawn. ( Experimental data. Solid line indicates curve adjusted through model Eq. (5) with $C F_{1}=1.7 \mathrm{e}^{-(k+\lambda) t}+265\left(1-\mathrm{e}^{-(k+\lambda) t}\right)$, where $k=$ Po elimination rate constant $\left(0.0693 \mathrm{~d}^{-1}\right)$ and $\lambda_{210 p_{0}}=$ radioactive decay constant for ${ }^{210} \mathrm{Po}\left(0.005 \mathrm{~d}^{-1}\right)$. Dashed line indicates model prediction through Eq. (5) for ${ }^{210} \mathrm{Po} C F$ in prawns due to seawater intake for osmoregulation, ' $O$ ' Equation is $C F_{t}=1.7 \mathrm{e}^{-(k+\lambda) t}+$ $9.8\left(1-\mathrm{e}^{-(k+\lambda) t}\right)$. 'S' corresponds to the fraction of ${ }^{210} \mathrm{Po} C F \mathrm{Cr}-$ cumulated through adsorption on external surface of prawns. Both lines start at $C F_{0}=1.7$, corresponding to the initial ${ }^{210}$ po (21. $\mathrm{mBq} \mathrm{g} \mathrm{g}^{-1}$ ) in prawns

ination of natural ${ }^{210} \mathrm{Po}\left(T_{\mathrm{b} 1 / 2}=11 \mathrm{~d}\right)$ in the same organ (fit of a single exponential to ${ }^{210} \mathrm{Po}$ data given in Table 3). In gonad and bone, the trend of ${ }^{208}$ Po concentration with time shows a slow increase due to the accumulation of ${ }^{208}$ Po being gradually transferred from other internal organs.

The whole-body elimination curve of ${ }^{208} \mathrm{Po}$ ingested with food displays 2 components (Fig. 5). Component I, $T_{\mathrm{b} 1 / 2}=0.6 \mathrm{~d}$, based on a single point, corresponds to the gut transit of unabsorbed labelled food. Gut transit times in teleost fish range between 0.5 and $2 \mathrm{~d}$ for temperatures from 15 to $24^{\circ} \mathrm{C}$ (Kapoor et al. 1975). Component II, $T_{b 1 / 2}=5 \pm 1 \mathrm{~d}$, probably corresponds to the cycling of ${ }^{208} \mathrm{Po}$ in liver and other internal tissues. The $y$-intercept of the best-fit line of this component provides an estimate of the absorbed fraction $(A)$, i.e. $0.048 \pm 0.024$ of the ingested ${ }^{208} \mathrm{Po}$. However, from Day 8 onwards, the ${ }^{208}$ Po elimination data further suggest that another component may be involved in $\mathrm{Po}$ retention in fish. This component (not shown) may account for ca $15 \%$ of the absorbed ${ }^{208} \mathrm{Po}(0.7 \%$ of the ingested dose) and would turnover much slower $\left(T_{\mathrm{b} 1 / 2} \approx 25 \mathrm{~d}\right)$ than Component I. The biological half-life of this long-lived component compares well with the biological half-life of the elimination of natural ${ }^{210} \mathrm{Po}$ in the same fish, $23 \mathrm{~d}$ (interval of fit 0 to $27 \mathrm{~d}$ ), that can be computed based on ${ }^{210} \mathrm{Po}$ data in Table 3.

Concentrations of ${ }^{210} \mathrm{Po}$ in tissues were highest at time zero of depuration period, i.e. measured about $2 \mathrm{~d}$ after the last feeding with natural food. These concentrations rapidly dropped, especially in liver and gonad, following the change to food low in ${ }^{210} \mathrm{Po}$ content. After Day $6,{ }^{208} \mathrm{Po}:{ }^{210} \mathrm{Po}$ ratios in whole body, liver and muscle became nearly constant, indicating that both isotopes were eliminated or transferred to other tissues at similar rates (Fig. 6). Gonad and bone displayed
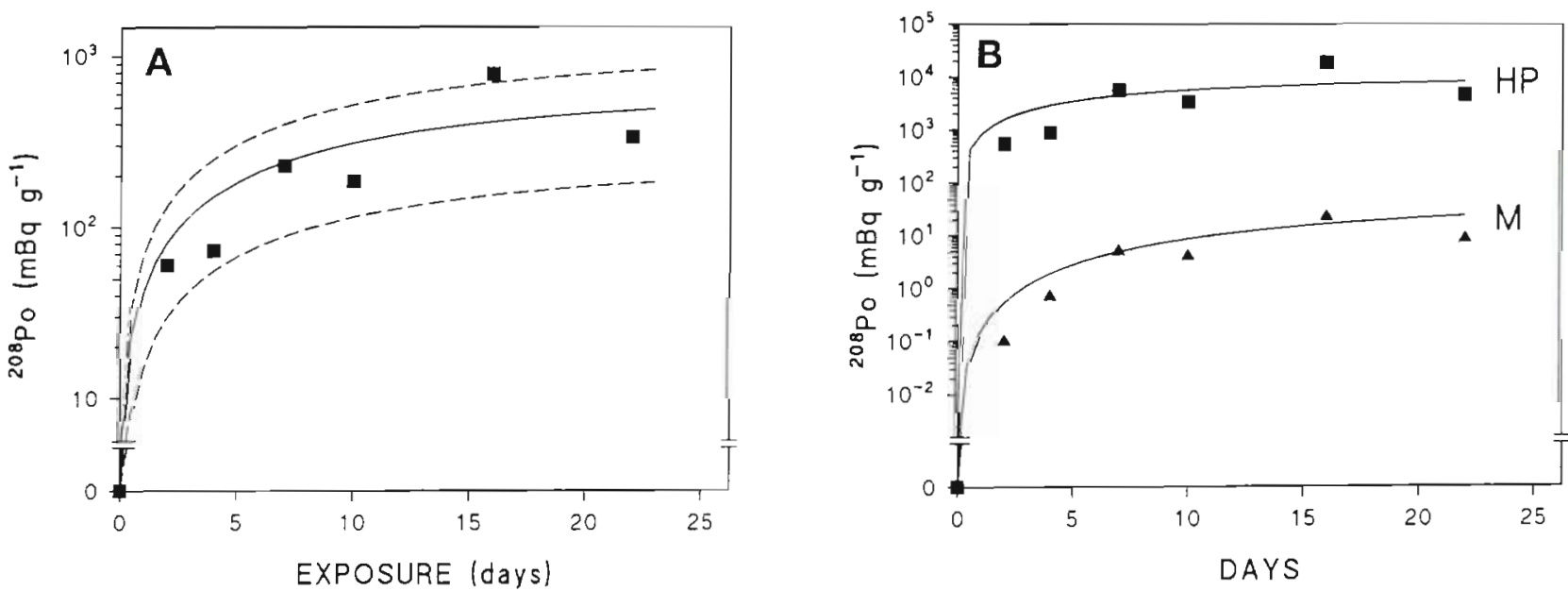

Fig. 4. Palaemon serratus. (A) Whole-body ${ }^{208}$ Po concentration accumulated from labelled food over time in prawn. (ロ) Experimental data. Solid line calculated through model Eq. (9), with $k=0.0693 \mathrm{~d}^{-1}, \lambda=-0.00065 \mathrm{~d}^{-1}, A=0.35, F_{\mathrm{r}}=0.05 \mathrm{~g}$ food g $\mathrm{g}^{-1}$ prawn $\mathrm{d}^{-1}$ Dashed lines account for variation in ${ }^{208} \mathrm{Po}$ concentration in food, $C_{1}=2.5 \pm 1.6 \mathrm{~Bq} \mathrm{~g}^{-1}$, during the exposure period. Arithmetically, dashed lines correspond to feeding rates of 8 and $2 \%$ of prawn body size, with all the other variables held constant.

(B) ${ }^{208}$ Po concentration in the hepatopancreas (HP) and muscle tissue (M) of prawns, following uptake from labelled food 
increasing ${ }^{208} \mathrm{Po}:{ }^{210} \mathrm{Po}$ ratio with time. reflecting a gradual accumulation of food-derived ${ }^{2 n}$ po during the period of observation.

These results confirm that in fish Po is readily absorbed from ingested food. ${ }^{203}$ Po was rapidly incorporated in fish liver and muscle and was metabolised (eliminated) at the same rate as the naturally occurring ${ }^{210} \mathrm{Po}$ in those organs. However, the single input of ${ }^{208}$ Po did not attain isotopic equilibrium in the organs with slower turnover rates (gonad and bone) during the observation period. Nevertheless, the observed similarities in the turnover of both Po isotopes in whole fish support the assumption of their identical physiological behaviour.

In the second experiment (Group II), fish were exposed to ${ }^{210}$ Po dissolved in seawater and were regularly fed with ${ }^{208} \mathrm{Po}$-labelled shrimp. Results of ${ }^{208} \mathrm{Po}$ and ${ }^{210} \mathrm{Po}$ measurements in fish tissues are presented in Table 4. From Day 2 onwards, concentrations of both isotopes were highest in the digestive tube, particularly in the intestine. High concentrations of ${ }^{210} \mathrm{Po}$ in these organs are characteristically found in fish in the natural environment (see 'Introduction'). They are partially due to incomplete removal of gut contents before the analysis. Since Po levels in intestine are highly variable and gut content is not considered as part of the fish tissues, we did not include the intes-

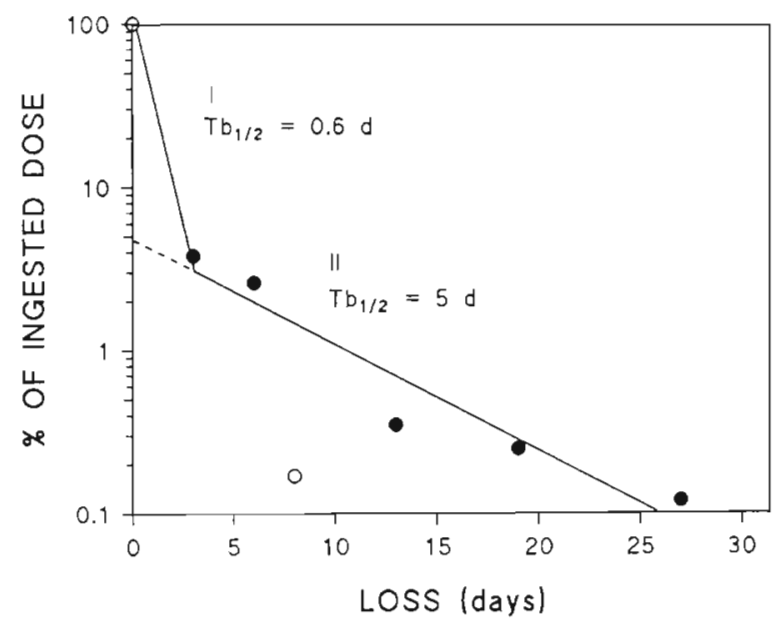

Fig. 5. Serranus scriba. Group I. Retention of ${ }^{208}$ Po in fish (reconstituted, excluding gut) following a single feeding with ${ }^{208}$ Po-labelled food. The equation of the least squares fit to the absorbed fraction ( 1 value excluded: 0 ) is $y=1.58( \pm 0.40)$ $\mathrm{e}^{-0.149( \pm 0.025) t}, \mathrm{R}^{2}=0.922, \mathrm{n}=5$, interval of fit 3 to $27 \mathrm{~d}$. The global equation of \% retention, $R$, of the ingested dose of ${ }^{208} \mathrm{Po}$ as a function of time $t(\mathrm{~d})$ is $R_{t}=95.2 \mathrm{e}^{-1.69 t}+4.8 \mathrm{e}^{-0.149 t}$ tine when reconstituting the whole-body Po concentrations in fish.

Results from this experiment also show that ${ }^{208}$ Po in food was absorbed and rapidly accumulated in liver and muscle, whereas the observed transfer to gonad and bone was somewhat slower. On a whole-body
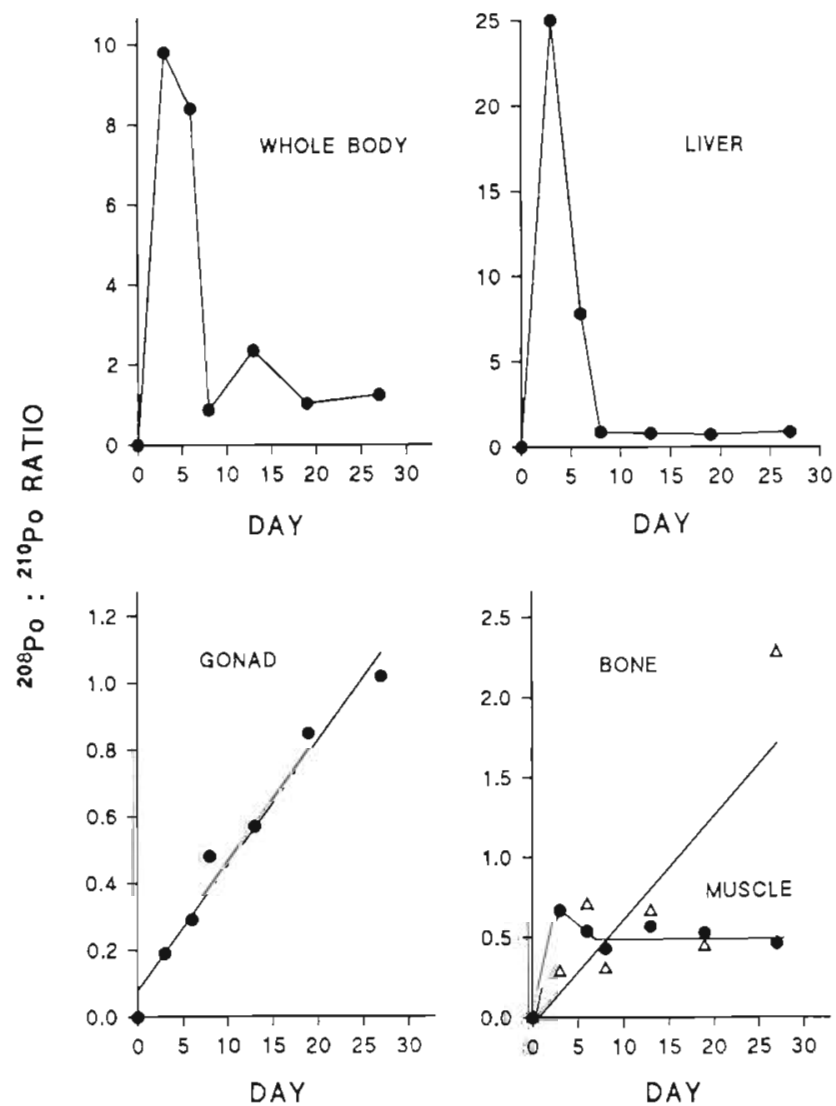

Fig. 6. Serranus scriba. Group I. ${ }^{208}$ po: ${ }^{210}$ Po ratio in whole fish and fish tissues following a single feeding with ${ }^{208} \mathrm{Po}$-labelled food. Constant ratios in whole body, liver and muscle indicate that both isotopes of Po turned over at the same rate 


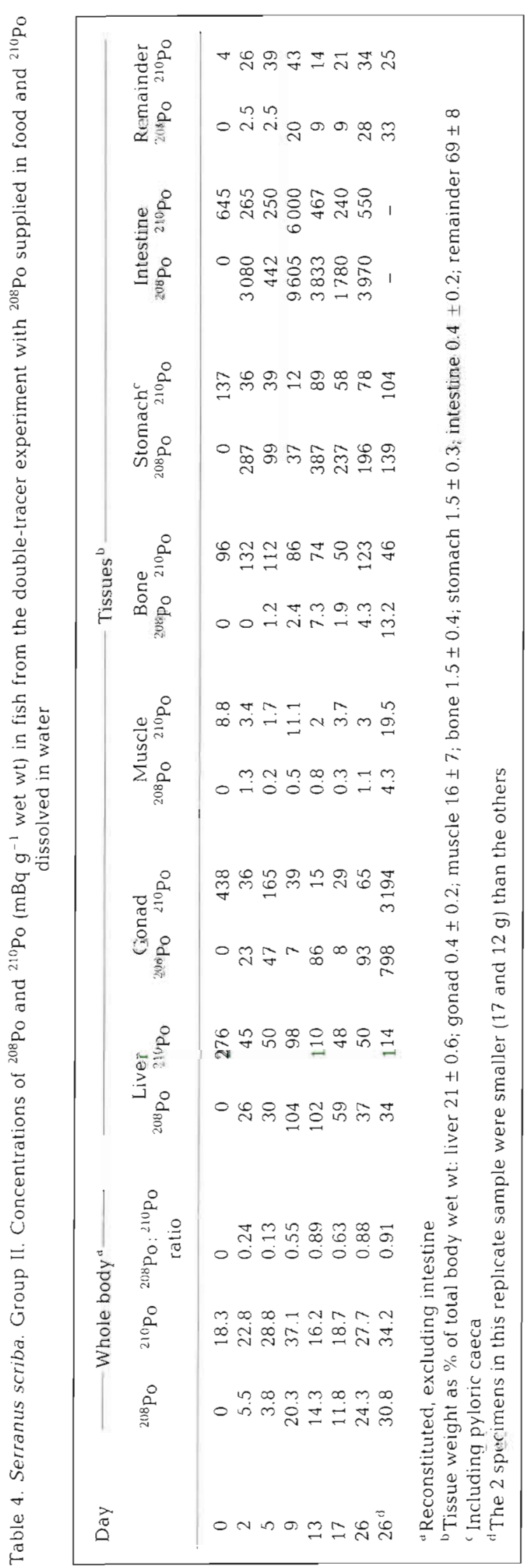

basis the specific activity of ${ }^{208} \mathrm{Po}$ derived from food increased regularly with an average daily increment of $0.94 \mathrm{mBq} \mathrm{g}^{-1} \mathrm{~d}^{-1}$, reaching ca $31 \mathrm{mBq} \mathrm{g}^{-1}$ by Day 26 (Table 4). During the exposure period, the whole-body ${ }^{210} \mathrm{Po}$ concentration in fish, which was $18 \mathrm{mBq} \mathrm{g}^{-1}$ at time zero, fluctuated between 16.0 and $37.0 \mathrm{mBq} \mathrm{g} \mathrm{g}^{-1}$ without showing any definite temporal trend. Statistical analyses suggest that these whole-body fluctuations are linked to ${ }^{210} \mathrm{Po}$ concentrations in the remainder fraction $\left(\mathrm{R}^{2}=0.622, \mathrm{p}<0.01\right)$ which includes surficial tissues directly exposed to the water. Weak correlation (muscle) or no correlation (liver, bone) between ${ }^{210}$ Po concentration in tissues and whole-body concentration further indicate that variations of ${ }^{210} \mathrm{Po}$ concentration in whole fish were not due to accumulation in internal tissues. It is noteworthy that before the experimental exposure, the ${ }^{210} \mathrm{Po}$ concentration factor in fish relative to the natural levels of ${ }^{210} \mathrm{Po}$ in seawater (ca $1 \mathrm{mBq} \mathrm{l^{-1 }}$ ) was $1.4 \times 10^{4}$. However, the identically computed $C F$ for the experimental exposure was only ca 4 . Thus, the substantial increase of ${ }^{210} \mathrm{Po}$ concentration in seawater, $8.3 \times 10^{3}$ times the normal value, did not produce a significant change in the ${ }^{210}$ Po concentration in fish. Nevertheless, the repeated ingestion of ${ }^{208} \mathrm{Po}$-labelled food resulted in the accumulation of this isotope reaching concentrations comparable to natural ${ }^{210} \mathrm{Po}$ levels. This is particularly striking because the concentration of ${ }^{208} \mathrm{Po}$ in food was reasonably low $\left(1.7 \mathrm{~Bq} \mathrm{~g}{ }^{-1}\right)$, whereas the concentration of ${ }^{210} \mathrm{Po}$ in water was very high.

The percent contribution of each tissue to the sum of specific activities of each polonium isotope in Serranus scriba is depicted in Fig. 7. ${ }^{208}$ Po taken up from food was rapidly distributed in a manner very similar to the distribution of natural ${ }^{210} \mathrm{Po}$ in control fish. Furthermore, as ${ }^{210} \mathrm{Po}$ dissolved in water was not substantially accumulated either in external or internal tissues, the relative distribution of this isotope remained pratically unchanged with time.

Uptake of ${ }^{210}$ Po from water by fish can occur through both ingestion of water for osmoregulation and adsorption onto external surfaces. Gills of marine teleosts appear to be impermeable to exchange of divalent ions (Conte 1969). The intake rate of water (drinking reflex) in marine teleosts usually corresponds to 0.3 to $1.5 \%$ of body weight $\mathrm{h}^{-1}$ (Conte 1969), and in Serranus scriba it is reported to be $0.120 \mathrm{ml} \mathrm{g}^{-1} \mathrm{~d}^{-1}$ (Motais \& Maetz 1965). Under the conditions of our experiment this corresponds to an intake rate of $1 \mathrm{mBq}{ }^{210} \mathrm{Po} \mathrm{g}^{-1} \mathrm{~d}^{-1}$. Assuming that ${ }^{210} \mathrm{Po}$ dissolved in water is absorbed through the gut walls with the efficiency of 1.0 , which is certainly an upper limit, such an uptake would result in a theoretical maximum steady-state ${ }^{210}$ Po concentration in whole fish of $7 \mathrm{mBq} \mathrm{g}^{-1}$. Due to precipitation of divalent ions in the lumen of the intestine, the accumu- 

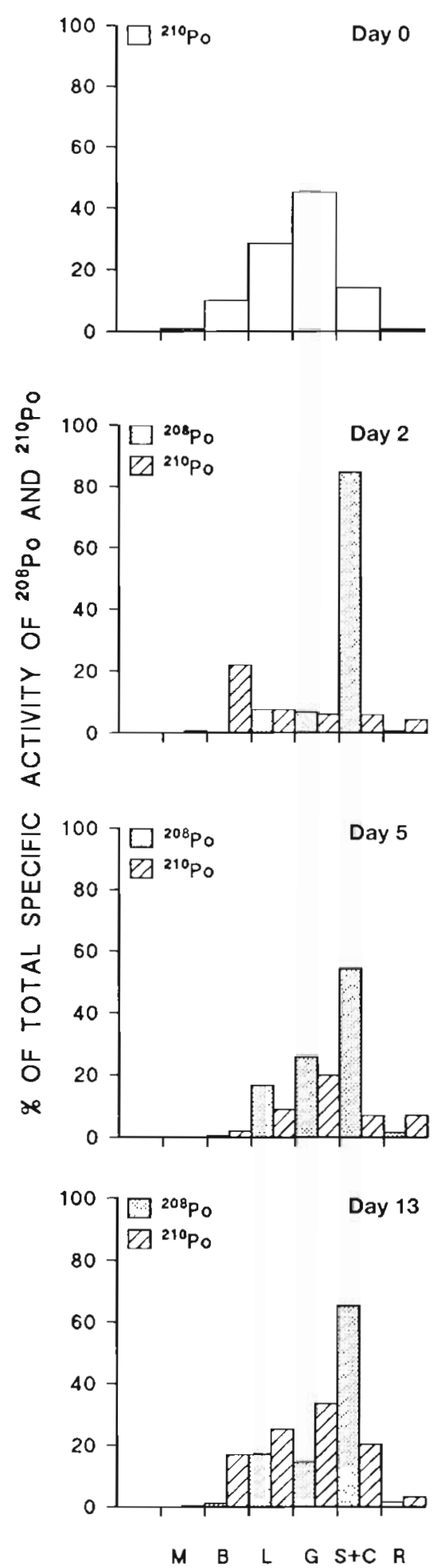

Fig. 7. Serranus scriba. Group II. Percent contribution of each tissue to the sum of specific activities for each Po isotope. Source of ${ }^{208} \mathrm{Po}$ was the food and source of ${ }^{210} \mathrm{Po}$ was the seawater. Distribution at Day 0 (control) displays the naturally occurring ${ }^{210}$ Po. $M$ : muscle; B: bone; L: liver; G: gonad; $\mathrm{S}+\mathrm{C}$ : stomach and pyloric caeca; R: remainder lation of ${ }^{210}$ Po from ingested seawater would likely be much lower. Additionally, the naturally occurring ${ }^{210} \mathrm{Po}$ in the food, $66 \mathrm{mBq} \mathrm{g}^{-1}$, would have contributed a further ca $1 \mathrm{mBq} \mathrm{g}^{-1}$ to the ${ }^{210} \mathrm{Po}$ burden in fish. However, the whole-body ${ }^{210} \mathrm{Po}$ concentrations determined in reconstituted fish (Table 4 ) are somewhat higher than the estimate $\left(8 \mathrm{mBq} \mathrm{g^{-1 }}\right)$ given above based solely on the drinking reflex and the natural ${ }^{210} \mathrm{Po}$ in food. This observation suggests that some other uptake pathway, e.g. surface adsorption, contributed to the ${ }^{210} \mathrm{Po}$ body burden of these fish. In fact, the remainder portion of the fish, which includes all external tissues that were in direct contact with the labelled seawater, contained 42 to $82 \%$ of the ${ }^{210} \mathrm{Po}$ body burden from Day 5 onwards. Nevertheless, uptake from water by all routes resulted in no more than a 2 -fold increase over the initial ${ }^{210} \mathrm{Po}$ concentration in fish (Table 4 ).

Data on the accumulation of ${ }^{208} \mathrm{Po}$ from food in Serranus scriba were fitted to Eq. (9) (Fig. 8). The ${ }^{208} \mathrm{Po}$ concentrations are adequately fitted using the assimilation efficiency of 0.048 determined in Group I fish. The fluctuation in the observed fish feeding rate

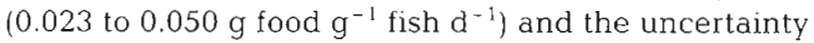
associated with the assimilation efficiency value $( \pm 25 \%)$ result in the observed spread in the experimental data shown in Fig. 8.

The contribution of Po sources to environmental levels of ${ }^{210} \mathrm{Po}$ in fish can be assessed by using the experimentally determined rate coefficients and natural ${ }^{210} \mathrm{Po}$ concentrations in model Eqs. (4) \& (9) above. Computations show that the contribution of ${ }^{210} \mathrm{Po}$ dissolved in

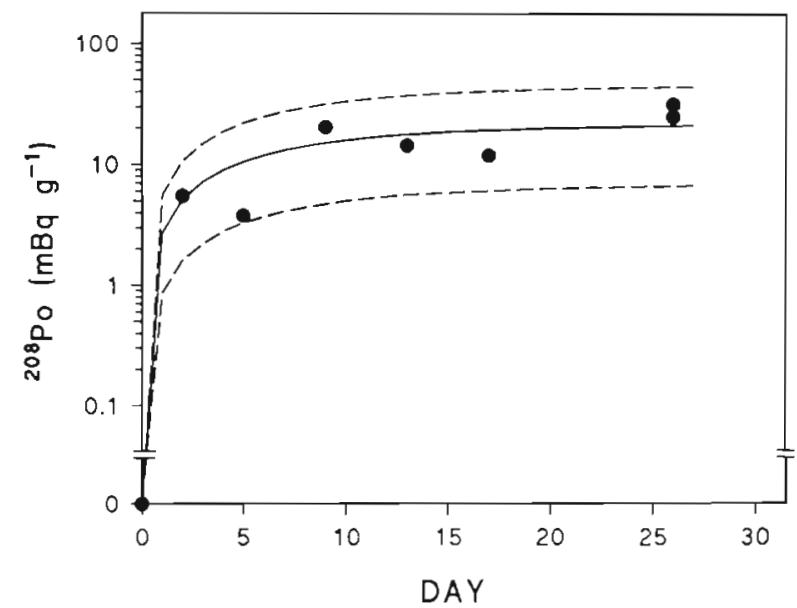

Fig. 8. Serranus scriba. Group II. Whole-body uptake of ${ }^{208} \mathrm{Po}$ from food over time. (O) Experimental results. Solid line calculated through model Eq. (9), with $C_{1}=1.7 \mathrm{~Bq} \mathrm{~g}^{-1}, A=0.048$,

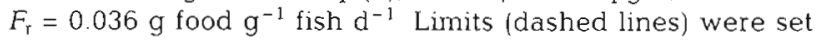
up with the following conditions: upper line, maximum food ingestion rate observed, $F_{\mathrm{r}}=0.050 \mathrm{~g}$ food $\mathrm{g}^{-1}$ fish $\mathrm{d}^{-1}$ and

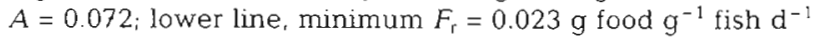
and $A=0.024$ 
seawater accounts for the accumulation of ca $4 \mu \mathrm{Bq} \mathrm{g} \mathrm{g}^{-1}$ in fish. If we consider the food source, assuming the ingestion of prey with a ${ }^{210} \mathrm{Po}$ concentration of $100 \mathrm{mBq}$ $\mathrm{g}^{-1}$ (e.g. mussels), an average feeding rate of $0.20 \mathrm{~g}$ food $\mathrm{g}^{-1}$ fish $\mathrm{d}^{-1}$ characteristic of predator fish in environmental conditions (Caddy \& Sharp 1986) and a ${ }^{210} \mathrm{Po}$ assimilation efficiency of 0.05 results in a wholebody ${ }^{210} \mathrm{Po}$ concentration of $7.2 \mathrm{mBq} \mathrm{g}^{-1}$ in fish. Therefore, the uptake of dissolved ${ }^{210} \mathrm{Po}$ would account for no more than $0.1 \%$ of the total ${ }^{210} \mathrm{p}_{\mathrm{O}}$ measured in fish.

\section{DISCUSSION AND CONCLUSIONS}

Results from the radiotracer experiments with prawns have demonstrated that Po bound to food is efficiently absorbed $(A=0.35)$ and accumulated in these crustaceans. Whereas Po supplied in the food is absorbed and distributed in the prawn tissues in a manner similar to the distribution of natural ${ }^{210} \mathrm{Po}$ in prawns, Po dissolved in water is mainly adsorbed on external surfaces.

Experiments on the uptake pathways of Po in fish furnished clear evidence that polonium dissolved in water is only weakly accumulated either on external surfaces or within internal organs. The principal pathway for Po bioaccumulation in fish is through digestive absorption, as shown by the absorption of ${ }^{208} \mathrm{Po}$ from food which rapidly accumulated and distributed in fish organs in a manner similar to the distribution of natural ${ }^{210} \mathrm{Po}$.

Whereas surface adsorption of ${ }^{210}$ Po played a major role in the experimental uptake of this radionuclide by prawns, this was not the case with fish. Strong Po adsorption onto prawn exoskeleton is most likely due to chelation of the radionuclide by functional groups on the chitinous portion of the cuticle as has been found for other trace elements (Stumm 1992). In the case of fish, surface adsorption of ${ }^{210} \mathrm{Po}$ is far less important, either owing to the different chemical binding properties of the mucous layer covering skin or because of the continued renewal of this mucous Some gut absorption of ${ }^{210} \mathrm{Po}$ from scawater occurs in crustaceans through the intake of water for osmotic regulation, whereas the drinking water reflex in teleost fish does not result in significant intake of this radionuclide. Particularly high concentrations of $\mathrm{P}_{0}$ were observed in fish intestine. Co-precipitation of Po with carbonate and sulfate ions from ingested seawater in the lumen of the intestine (Conte 1969) is the most likely mechanism for the buildup of $\mathrm{Po}$ in this organ. White mucous corpuscles of $\mathrm{Ca}$ and $\mathrm{Mg}$ carbonates containing very high concentrations of $\mathrm{Cd}, \mathrm{Zn}, \mathrm{Cu}$ and $\mathrm{Pb}$ have been observed in fish intestine (NoelLambot 1981). These corpuscles are regularly evacu- ated and may constitute a defense mechanism to limit the absorption of metal cations from seawater through the intestinal wall (Noel-Lambot 1981). In any event. all our data indicate that the main pathway of Po uptake in both crustaceans and fish is through ingestion of food, which accounts for $>97$ and $>99 \%$, respectively, of the ${ }^{210} \mathrm{Po}$ in environmental samples.

In studies on Po absorption through the gut of shrimp, prawns and fish, different procedures have been used in the preparation of labelled food, ranging from passive sorption of the radionuclide onto food particles (Carvalho \& Fowler 1993) to prolonged Po incorporation from water and food into prey subsequently used to feed experimental organisms (this study). Comparison of the results obtained using these procedures indicates that following ingestion, Po loosely bound to food particles is only partially absorbed into internal tissues, whereas Po incorporated in the organic matrix of prey is efficiently absorbed and its distribution in predator tissues more closely matches the distribution of the naturally occurring ${ }^{210} \mathrm{P}$. This observation suggests that the efficiency of $P_{0}$ absorption and subsequent metabolism depends upon incorporation of the radionuclide into the organic matrix of food.

Our results are also in agreement with recent findings which demonstrate that the assimilation efficiency of metals and metaloids in copepods is directly related to the concentration of these elements in the cytoplasm (readily assimilable proteins) of phytoplankton used for food (Fisher \& Reinfelder 1991, Reinfelder \& Fisher 1991). Protein assimilation efficiencies reported for decapod crustaceans were spread over a wide range of values depending upon the protein requirements of the species, the enzymatic capabilities for digestion and the degree to which the food can be digested. For example, penaeid shrimp, like other crustaceans, require diets containing 23 to $55 \%$ protein (Dall et al. 1990). In our experiment, mussel flesh used to feed prawns contained approximately $40 \%$ protein. As protein assimilation efficiency in Palaemon serratus is reported to be 80 to $92 \%$ (Dall \& Moriartry 1983), an average absorption coefficient of $0.34(0.40 \times 0.86)$ of the food consumed can be estimated. In carnivorous fish, the absorption efficiency of protein has been consistently determined at $80 \%$, although assimilation efficiency is subject to the same constraints of the ability of fish to digest and absorb protein from food (Cowey \& Sargent 1972, Conover 1978, Smith 1989). A natural fish food consisting of invertebrates can contain up to $11.5 \%$ protein (Phillips 1976). In our fish experiments, shrimp tissues fed to the perch contain ca 10\% protein (Waterman 1960) which results in an approximate $0.08(0.10 \times 0.80)$ absorption coefficient for food. Although these general figures are strongly 
dependent upon consumer species and food type, tentatively they can be compared with the assimilation efficiencies of Po determined in this study, viz. 0.35 for prawns and 0.048 for fish. Regardless of the differences in food type, feeding strategies and digestive systems of organisms from many different groups, it seems plausible that the assimilation of Po depends primarily on binding to assimilable organic molecules and, more specifically, to proteins. Thus, the availability of ${ }^{210} \mathrm{Po}$ from different food types with respect to protein content is clearly an important aspect for future study.

Given that the food chain is the primary transfer pathway for Po in the organisms tested, ${ }^{210} \mathrm{Po}$ concentrations in these organisms should reflect the ${ }^{210} \mathrm{Po}$ content of their prey to a degree dependent upon the food assimilation efficiency and the ${ }^{210}$ Po excretion rate. The high assimilation efficiency of Po from food observed in shrimp (Carvalho \& Fowler 1993) and prawns (this study) suggests that this is a common feature among crustaceans. Still higher Po assimilation efficiencies may exist in zooplankton crustaceans (e.g copepods, euphausiids, mysids), a fact which would sactisfactorily explain the enhanced Po levels and the high ${ }^{210} \mathrm{Po}:{ }^{210} \mathrm{~Pb}$ ratios (10 to 1000 ) frequently measured in these pelagic heterotrophic species. Although this would require experimental verification before a general conclusion can be drawn, the proposed usefulness of ${ }^{210} \mathrm{Po}$ as a natural tracer in diet studies of marine macroorganisms (Heyraud et al. 1988, Cherry et al 1989 ) is well supported by our findings.

Our experimental results and the modelling of Po accumulation in prawn and fish also highlight the importance of the feeding rate in governing the concentration of ${ }^{210} \mathrm{Po}$ in marine organisms. In addition, the fluctuation of ${ }^{210} \mathrm{Po}$ concentration in the ingested food, either due to changes in diet composition or to variable ${ }^{210}$ Po concentrations in the prey, will result in fluctuations of ${ }^{210} \mathrm{Po}$ content in predator organisms, as has frequently been observed in different samples of the same species (Carvalho 1990).

The simultaneous use of 2 Po isotopes in a simple food chain allowed following the bioaccumulation of ${ }^{208} \mathrm{Po}$ through the digestive pathway and ${ }^{210} \mathrm{P}$ o uptake from the ambient water, with virtually no mixing or interference between the isotopes. These initial results will hopefully encourage further application of this technique in studies on the biological cycling and metabolism of Po. In particular, the double-tracer technique offers a means for examining more complex Po transfer pathways in studies related to the enhancement of environmental ${ }^{210} \mathrm{Po}$ levels by non-nuclear industries.

Another area of current interest in biogeochemistry is the use of ${ }^{210} \mathrm{Po}$ and ${ }^{210} \mathrm{~Pb}$ as tracers of vertical flux processes and mean residence time of particles in the upper layer of the ocean (Fowler \& Knauer 1986. Ritchie \& Shimmield 1991). For example, using the double-tracer technique, ${ }^{210} \mathrm{Po}$ incorporation in biogenic detrital particles formed through zooplankton grazing and molting could be compared with ${ }^{210} \mathrm{Po}$ adsorption from water as competing mechanisms in the overall process of ${ }^{210} \mathrm{Po}$ scavenging in marine waters.

Acknowledgements. Thanks to N. S. Fisher, R. D. Cherry and an anonymous reviewer for the critical comments which substantially improved the manuscript. The IAEA Marine Environment Laboratory operates under an agreement between the International Atomic Energy Agency and the Government of the Principality of Monaco.

\section{LITERATURE CITED}

Broecker, W. S., Peng, T. H. (1982). Tracers in the sea. Eldigio Press, New York

Caddy, J. F., Sharp, G. D. (1986). An ecological framework for marine fishery investigations. F.A.O. Fish. Tech. Pap. No. 283. F.A.O., Rome

Carvalho, F. P., Fowler, S. W. (1985). Biokinetics of plutonium, americum and californium in the marine isopod Cirolana borealis, with observations on its feeding and molting behaviour. Mar. Biol. 89: 173-181

Carvalho, F. P. (1988a). ${ }^{210} \mathrm{Po}$ in marine organisms: a wide range of natural radiation dose domains. Radiat. Protect. Dosim. 24: 113-117

Carvalho, F. P. (1988b). Polonium-210 in marine fish. Rapp. P.-v, Réun. Comm. int. Explor. scient. Mer Méditerr. 31 (2): 246

Carvalho, F. P. (1990). Contribution a l'étude du cycle du polonium-210 et du plomb-210 dans l'environnement. Thèse de Doctorat, Université de Nice-Sophia Antipolis

Carvalho, F. P., Fowler, S. W. (1993). An experimental study on the bioaccumulation and turnover of polonium-210 and lead-210 in marine shrimp. Mar. Ecol. Prog. Ser 102: $125-133$

Cherry, R. D., Heyraud, M. (1981). Polonium-210 content of marine shrimp: variation with biological and environmental factors. Mar. Biol. 65: 165-175

Cherry, R. D., Heyraud, M. (1982). Evidence of high natural radiation doses in certain mid-water oceanic organisms. Science 218: 54-56

Cherry, R. D., Heyraud, M., James, A. G. (1989). Diet prediction in common clupeoid fish using polonium-210 data. J. environ. Radioact. 10: 47-65

Conover, R. J. (1978). Transformation of organic matter. In: Kinne, O. (ed.) Marine ecology, Vol. IV, Dynamics. John Wiley \& Sons, New York, p. 221-499

Conte, F. P. (1969). Salt secretion. In: Hoar, W. S., Randall, D. J. (eds.) Fish physiology, Vol I. Academic Press, Inc., New York, p. 241-292

Cowey, C. B., Sargent, J. R. (1972). Fish nutrition. Adv. mar. Biol. 10: 383-492

Dall, W., Moriartry, D. J. W. (1983). Functional aspects of nutrition and digestion. In: Mardel, L. H. (ed.) The biology of Crustacea, Vol. 5, Internal anatomy and physiological regulation. Academic Press, Inc., New York, p. $215-261$ 
Dall, W. Hill, B. J., Rothlisberg, P. C., Sharples, D. J. (1990) The biology of Penaeidae. Adv. mar. Biol. 27: 1-489

Fisher, N. S., Reinfelder, J. R. (1991). Assimilation of selenium in the marine copepod Acartia tonsa studied with a radiotracer ratio method. Mar. Ecol. Prog. Ser. 70: 157-164

Fleer, A. P., Bacon, M. P. (1984). Determination of ${ }^{210} \mathrm{~Pb}$ and ${ }^{210} \mathrm{Po}$ in seawater and marine particulate matter. Nuc Instrum. Methods phys. Res. 223: 243-249

Flynn, W. W. (1968). The determination of low-levels of polonium-210 in environmental materials. Analytica chim. Acta 43: 221-227

Fowler, S. W., Knauer, G. A. (1986). Role of large particles in the transport of elements and organic compounds through the oceanic water column. Prog. Oceanogr. 16: 147-194

Heyraud, M. Cherry, R. D. (1979). Polonium-210 and lead210 in marine food chains. Mar. Biol. 52: 227-236

Heyraud, M., Cherry, R. D., Dowdle, E. B. (1987). The subcelIular localization of natural ${ }^{210} \mathrm{Po}$ in the hepatopancreas of the rock lobster (Jasus lalandii). J. environ. Radioact. 5 : $249-260$

Hoffman, F. L., Hodge, V. F., Folsom, T R. (1974), ${ }^{210} \mathrm{Po}$ radioactivity in certain mid-water fish of the Eastern Temporal Pacific. Health Physics 26: 65-70

Kapoor, B. G., Smit, H., Verighina, I. A. (1975). The alimentary canal and digestion in teleosts. Adv. mar. Biol. 13: 109-239

Koster, H. W., Marwitz, P. A., Berger, G. W., van Weers, A. W., Hagel, P., Nieuwenhuize, J. $(1992) .{ }^{210} \mathrm{Po},{ }^{210} \mathrm{~Pb}$ and ${ }^{226} \mathrm{Ra}$ in Dutch aquatic ecosystems and polders, anthropogenic sources, distribution and radiation doses. Radiat. Protect. Dosim. 45(1/4): 715-719

Motais, R., Maetz, J. (1965). Comparaison des échanges de sodium chez un teleosteen euryhaline (le Flet) et un teleostéen sténohalin (le Serran) en eau de mer Importance relative du tube digestif et de la branchie dans ces échanges. C.r. Acad. Scl., Paris 261: 532-535

Noel-Lambot, F. (1981). Presence in the intestinal lumen of marine fish of corpuscles with a high cadmium-, zinc-, and

This article was submitted to the editor copper-binding capacity: a possible mechanism of heavy metal tolerance. Mar. Ecol. Prog. Ser. 4: 175-181

Pentreath, R. J. (1973). The accumulation from water of ${ }^{65} \mathrm{Zn}$, ${ }^{54} \mathrm{Mn},{ }^{58} \mathrm{Co}$ and ${ }^{58} \mathrm{Fe}$ by the mussel Mytilus edulis. J. mar. biol. Ass. U.K. 53: 127-143

Phillips, A. M. (1976). Nutrition, digestion and energy utilization. In: Hoar, W. B., Randall, D. J. (eds.) Fish physiology, Vol 1 Academic Press, Inc., New York, p. $391-432$

Reinfelder, J. R., Fisher, N. S. (1991). The assimilation of elements ingested by marine copepods. Science 251: $794-796$

Ritchie, G. D., Shimmield, G. B. (1991). The use of ${ }^{210} \mathrm{Po} /{ }^{210} \mathrm{~Pb}$ disequilibria in the study of the fate of marine particulate matter. In: Kershaw, P. J., Woodhead, D. S. (eds.) Radionuclides in the study of marine processes. Elsevier Applied Science, London, p. 142-153

Smith, L. S. (1989). Digestive functions in teleost fishes. In: Halver, J. E. (ed.) Fish nutrition, 2nd edn. Academic Press, Inc., New York, p. 332-421

Spaargaren, D. H. (1972). Osmoregulation in the prawns Palaemon serratus and Lysmata seticaudata from the Bay of Naples. Neth. J. Sea Res. 5(4): 416-436

Skwarzec, B., Bojanowski, R. (1988). ${ }^{210}$ po content in seawater and its accumulation in southern Baltic plankton. Mar. Biol. 97: 301-307

Stumm, W. (1992). Chemistry of the solid-water interface. John Wiley \& Sons, Inc., New York

Swift, D. J., Pentreath, R. J. (1988). The accumulation of plutonium by the edible winkle (Littorina littorea L.). J. environ. Radioact. $7: 29-48$

Todd, J F., Wong, G. T F., Reid, D. F. (1986). The geochemistries of ${ }^{210} \mathrm{Po}$ and ${ }^{210} \mathrm{~Pb}$ in waters overlying and within the Orca Basin, Gulf of Mexico. Deep Sea Res. 33 (10): 1293-1306

Waterman, T H. (1960). The physiology of Crustacea. Academic Press, New York

Manuscript first received: June 28, 1993

Revised version accepted: October 28, 1993 